Research Articles: Behavioral/Cognitive

\title{
Age-related enhancements in positive emotionality across the lifespan: structural equation modelling of brain and behaviour
}

https://doi.org/10.1523/JNEUROSCI.1453-21.2022

Cite as: J. Neurosci 2022; 10.1523/JNEUROSCI.1453-21.2022

Received: 15 July 2021

Revised: 8 February 2022

Accepted: 11 February 2022

This Early Release article has been peer-reviewed and accepted, but has not been through the composition and copyediting processes. The final version may differ slightly in style or formatting and will contain links to any extended data.

Alerts: Sign up at www.jneurosci.org/alerts to receive customized email alerts when the fully formatted version of this article is published.

Copyright (C) 2022 Stretton et al.

This is an open-access article distributed under the terms of the Creative Commons Attribution 4.0 International license, which permits unrestricted use, distribution and reproduction in any medium provided that the original work is properly attributed. 
Title: Age-related enhancements in positive emotionality across the lifespan: structural equation modelling of brain and behaviour

\section{Abbreviated Title: Positivity across the life-span}

Authors: Jason Stretton ${ }^{1 *}$, Susanne Schweizer ${ }^{2 *}$, Tim Dalgleish ${ }^{1,3}$ for Cam-CAN ${ }^{4}$

\section{Author Affiliations:}

${ }^{1}$ Medical Research Council, Cognition and Brain Sciences Unit, 15 Chaucer Road, University of Cambridge, CB2 7EF

${ }^{2}$ Department of Psychology, University of New South Wales, NSW, 2052

${ }^{3}$ Cambridgeshire and Peterborough NHS Foundation Trust, CB21 5EF

${ }^{4}$ Cambridge Centre for Ageing and Neuroscience (Cam-CAN), University of Cambridge, CB2 1TN

*Authors should be considered co-first authors

\section{Corresponding Author:}

Jason Stretton; Email: Jason.stretton@ mrc-cbu.cam.ac.uk; Telephone: +44 1223355294

Number of Pages: 39

Number of Figures: 6

Number of Tables: 3

Number of Words;

Abstract; 240

Introduction; 928

Discussion; 702

Acknowledgements: The Cambridge Centre for Ageing and Neuroscience (Cam-CAN) research was supported by the Biotechnology and Biological Sciences Research Council (BB/H008217/1); TD, JS and SS are additionally supported by the UK Medical Research Council (MC_A060_5PQ60). TD is supported by the National Institute for Health Research Cambridge Biomedical Research Centre. We are grateful to the Cam-CAN respondents and their primary care teams in Cambridge for their participation in this study. We also thank colleagues at the MRC Cognition and Brain Sciences Unit MEG and MRI facilities for their assistance. The Cam-CAN corporate author consists of the project principal personnel: Lorraine K Tyler, Carol Brayne, Ed Bullmore, Andrew Calder, Rhodri Cusack, Tim Dalgleish, John Duncan, Rik Henson, Fiona Matthews, William Marslen-Wilson, James Rowe, Meredith Shafto; Research Associates: Karen Campbell, Teresa Cheung, Simon Davis, Linda Geerligs, Rogier Kievit, Anna McCarrey, Jason Taylor, Kamen Tsvetanov, Nintin Williams; Research Assistants: Lauren Bates, Tina Emery, Sharon Erzinçlioglu, Sofia Gerbase, Stanimira Georgieva, Claire Hanley, Beth Parkin, David Troy; Research Interviewers: Jodie Allen, Gillian Amery, Liana Amunts, Anne Barcroft, Amanda Castle, Cheryl Dias, Jonathan Dowrick, Melissa Fair, Hayley Fisher, Anna Goulding, Adarsh Grewal, Geoff Hale, Andrew Hilton, Frances Johnson, Patricia Johnston, Thea KavanaghWilliamson, Magdalena Kwasniewska, Alison McMinn, Kim Norman, Jessica Penrose, Fiona Roby, Diane Rowland, John Sargeant, Maggie Squire, Beth Stevens, Aldabra Stoddart, Cheryl Stone, Tracy Thompson, Ozlem Yazlik; and administrative staff: Dan Barnes, Marie Dixon, Jaya Hillman, Joanne Mitchell, Laura Villis. 
50 Author contributions: TD and SS conceived the study. JS analysed the data. TD, JS and SS

51 wrote the paper.

52

53 Conflict of Interest Statement;

54

55 The authors declare no competing financial interests

56

57

58

59

60

61 


\section{Abstract}

Aging is associated with a bias in attention and memories towards positive and away from negative emotional content. In addition, emotion regulation appears to improve with age, despite concomitant widespread cognitive decline coupled with gray matter volume loss in cortical and subcortical regions thought to sub-serve emotion regulation. Here, we address this emotion-aging paradox using the behavioural data of an emotion regulation task from a population derived, male and female, human sample (CamCAN) and utilise Structural Equation Modelling together with multivariate analysis of structural MRI images of the same sample to investigate brain-behaviour relationships. In a series of measurement models, we show the relationship between age and emotionality is best explained by a four-factor model, compared to single and hierarchical factor models. These four latent factors are interpreted as Basal Negative Affect, Positive Reactivity, Negative Reactivity and Positive Regulation (upregulating positive emotion to negative content). Increasing age uniquely contributes to increased Basal Negative Affect, Positive Reactivity and Positive Regulation, but not Negative Reactivity. Furthermore, we show gray-matter volumes, namely in the bilateral frontal operculum, medial frontal gyrus, bilateral hippocampal complex, bilateral middle temporal gyri and bilateral angular gyrus, are distinctly related to these four latent factors. Finally, we show that a subset of these brain-behaviour relationships remain significant when accounting for age and demographic data. Our results support the notion of an age-related increase in positivity and are interpreted in the context of the Socioemotional Selectivity Theory of improved emotion regulation in older age. 
95 Aging is associated with a paradoxical increase in well-being and improved emotion 96 regulation despite widespread cognitive decline and gray-matter volume loss in neural 97 regions which underlie emotion regulation. Using a population-derived sample we test the 98 theories behind this emotion-aging paradox with an emotion-regulation task and structural 99 MRI data. We report robust age-related increases in positivity across the lifespan and show 100 structural neural integrity influences this relationship with increasing age. Several brainbehaviour relationships remained unaffected by age and may represent empirically-derived 102 neural markers to explore the paradox of increased well-being in old age. The results support 103 the predictions of Socioemotional Selectivity Theory of improved emotion regulation in older 104 age and challenge the amygdala-focused neural predictions of the Aging Brain Model. 


\section{Introduction}

Current reported levels of personal well-being in the United Kingdom are at their highest after the age of 65 (ONS, 2016) . While ratings do fall from age 75 onwards, epidemiological surveys of self-reported life satisfaction and happiness in the over 90's remains higher than that of middle-aged individuals (ONS, 2016). This is supported by laboratory studies that reveal that healthy older adults report enhanced positive affect and greater emotional stability than their younger counterparts (Carstensen et al., 2000; Carstensen et al., 2011). Given the ubiquity of physical and cognitive decline associated with getting older, it is somewhat paradoxical that our twilight years are often the source of greatest satisfaction.

Socioemotional Selectivity Theory (SST) (Carstensen, 1992, 2006), an influential life-span theory of motivation, seeks to unravel this paradox. Specifically, SST suggests that adult life is governed by a core sets of goals broadly associated with either the acquisition of knowledge, resources and social connections or the regulation of emotions associated with well-being. The central tenet of SST is that the relative importance of these sets of goals changes as a function of future time horizons. When the future is perceived as lengthy, as is typical in youth, goals associated with acquisition to maximise future prospects are prioritised over those associated with more immediate positive emotionality and wellbeing. Conversely, when the future is perceived as constrained, typically as we get older, our goal priorities shift to become less future-oriented and more focused on the emotional satisfaction that is possible in the here and now. Other prominent theories in this domain similarly emphasize age-related shifts in strategic priorities and consequent behavioural preferences (Labouvie-Vief, 2003; Charles, 2010; Urry and Gross, 2010) .

A related theoretical view is that the greater emotional stability and wellbeing in older adults might also be a function of age-related increases in expertise in navigating emotive situations, either through more optimal selection of appropriate emotional regulation strategies or as a 
function of more effective and consolidated emotion-control skills (John and Gross, 2004; Birditt et al., 2005; Sims et al., 2015; Burr et al., 2020). Support for this latter view is mixed, however. Some studies are consistent, while others show no age-related changes in emotionregulation or declines in regulation capacity with age (Phillips et al., 2008; Urry and Gross, 2010; Winecoff et al., 2011; Opitz et al., 2014; Sims et al., 2015; Martins et al., 2018; Schweizer et al., 2018; Livingstone and Isaacowitz, 2019; Burr et al., 2020). One reason for these mixed data might be the reliance of several core emotion-regulation strategies - for example, reappraisal - on domain-general processes of cognitive-control (Ochsner and Gross, 2005), which appear to decline with age as a function of sharp neuronal degradation of the dorsolateral prefrontal cortex (dlPFC) (Braver and Barch, 2002).

However, differential structural trajectories of the sub-regions of the PFC may help to explain why older adults maintain function in other emotion processing contexts such as memory and attention. Prefrontal regions including the ventromedial prefrontal cortex (vmPFC) (Quirk and Beer, 2006; Winecoff et al., 2013) and anterior cingulate cortex (ACC) (Bush et al., 2000), both associated with emotion processing, have been shown to maintain their cortical thickness across the lifespan (Fjell et al., 2009b)

A compelling and competing account suggests age-related improvements in emotion regulation are caused by an age-related change in the amygdala response to affective stimuli, the aging-brain model (ABM) (Cacioppo et al., 2011). The ABM argues that the amygdala maintains it responsiveness to positive stimuli as we age, but diminishes in response to negative stimuli, thus biasing the attention to and subsequent memory of positive stimuli. Functional imaging evidence shows older adults have reduced amygdala activity in response to negative, but not positive pictures, relative to younger adults (Mather et al., 2004), while structural imaging and post-mortem studies indicate less volumetric decline and less 
182 histological effects of aging in the amygdala as a proxy of better preserved function (Allen et 183 al., 2005; Brabec et al., 2010).

184 Indeed, prominent theories of emotion regulation draw a distinction between effortful, 185 resource-demanding strategies and processes that have become automatic and thus less reliant 186 on declining cognitive control resources (Braunstein et al., 2017). There is now robust 187 support from laboratory studies that automatic cognitive processing biases in domains such as 188 attention and memory in favour of positive information - the so-called 'positivity effect' 189 are augmented with older age (Charles et al., 2003; Kennedy et al., 2004; Mather and 190 Carstensen, 2005) . It therefore follows that automatized emotion regulation processes 191 (including those that drawn upon attentional and mnemonic processes) that prioritise positive 192 affect become strengthened across the lifespan, while regulation processes that rely on 193 declining effortful cognitive control may become less effective. This might help to explain 194 the mixed findings regarding emotion-regulation and aging. Another important factor that 195 may partially account for these equivocal data is the tendency to for studies to use single bi196 valence scales (Schweizer et al., 2018), ranging from positive to negative, to measure 197 experienced affect. Single scales could obscure age-related increases in positive affectivity if 198 there are separate age-related effects for negative affectivity that act in an opposite direction.

199 A strength of the positivity effect literature (Charles et al., 2003; Kennedy et al., 2004; 200 Mather and Carstensen, 2005), is the disaggregation of positive and negative information. A 201 similar measurement separation in the domain of valence would be consistent with research 202 in affective neuroscience confirming the utility of discrete valence dimensions (Viinikainen 203 et al., 2010; Paulus et al., 2017).

\section{Current study}

205 The present study therefore used a gold-standard laboratory-based emotional reactivity and 206 regulation task (Schweizer et al., 2013; Schweizer et al., 2016) to examine age-related 
207 changes in elicited positive affectivity (assayed independently of negative affectivity) within

208 both passive viewing and emotion regulation contexts. We used a large population-derived 209 sample of adults aged 18-88 as part of the Cam-CAN cohort (www.cam-can.org (Shafto et 210 al., 2014)). We evaluated the hypothesis that the robust age-related positivity effect within the 211 cognitive domain extends to the affective domain, in the form of an age-dependent increase 212 in core components of positive affectivity. We predicted that such enhancement in positive 213 affectivity would be independent of any age-related changes in cognitive control measured 214 behaviourally. Finally, we examined the relationships between age-related effects in positive 215 affectivity and age-related differences in brain gray-matter, based on the Magnetic Resonance 216 (MR) measurements within the Cam-CAN cohort (Taylor et al., 2017). This allowed us to 217 evaluate whether any age-related enhancements in positive affectivity were also independent 218 of age-related volumetric changes in fronto-parietal brain regions typically associated with more effortful emotion regulation (Fjell et al., 2009a) using structural equation modelling

220 (SEM) to explore brain-behaviour relationships (Kievit et al., 2012).

\section{Materials and Methods}

\section{Participants}

223 Three-hundred and thirty of the Cam-CAN (Shafto et al., 2014) sample were invited to 224 perform an emotion reactivity and regulation task. Sixteen participants chose not to undertake 225 the task, and 26 participants were excluded as session notes indicated they did not follow the 226 instructions of the task appropriately. Fifteen participants did not complete our measure of 227 cognitive control - the Cattell Test $(n=9)$ - or provide demographic data $(n=6)$ and for an 228 additional 24 there were problems with the analysis of their MR images (Taylor et al., 2017). 229 Demographic data for the remaining 249 are shown in Table 1. All participants took part in a 230 range of psychological tests (no other cognitive domains were analysed in the context of this 231 analysis). Ethical approval for the study was obtained from the Cambridgeshire 2 (now East 
232 of England-Cambridge Central) Research Ethics Committee. Participants gave full

233 informed consent.

234 <nsert Table 1 here>

235 Experimental Design

236 Emotion Reactivity and Regulation Task (ERRT)

237 Emotion reactivity and regulation were assessed with a film-based paradigm (Schweizer et 238 al., 2013; Schweizer et al., 2016) (Figure 1). Participants viewed a series of forty 30-second 239 film clips that were either positive (e.g., babies laughing), neutral (e.g., weather report) or 240 negative (e.g., documentary of the Rwandan genocide) in valence and consisted of a mixture 241 of real-life and fictional footage. Participants received one of two different viewing 242 instructions before each clip. Either "WATCH", where participants were told to watch the 243 film clips and allow themselves to feel any emotions that naturally arose without trying to 244 deliberately distract themselves from the content of the film clip or effortfully regulate their 245 emotions in any way. The second viewing instruction "REGULATE" was only applicable to 246 half of the negative film clips. Here, participants were explicitly asked to try to reduce 247 (down-regulate) any unwanted distressing affect in response to the film clip by reappraising 248 the contents of the film clip. This gave four task conditions: Positive Watch; Negative Watch; 249 Negative Regulate; and Neutral Watch.

250 Before each film clip, participants received a prompt to indicate the valence and viewing 251 instruction for the clip (e.g. "WATCH NEUTRAL" or "REGULATE NEGATIVE"). This 252 was followed by the clip itself, after which participants rated on separate ten point scales both 253 their negative and positive affective reactions experienced during the clip, as well as rating 254 how much they simply watched the clip versus regulated their affect, as a measure of 255 compliance. This resulted in both mean negative and mean positive affective ratings for each 256 task condition in each participant. Each of the four conditions yielded a positive affect rating 
and a negative affect rating. Affective responses were rated on a scale ranging from ' 1 ' $=$ not

258 at all, to ' 11 ' = extremely. Instruction compliance was rated on a scale ranging from ' 1 ' $=$

259 Watch, to ' 11 ' = Regulate. Therefore 8 ratings were utilised for modelling purposes to

260 disaggregate the positive and negative affective ratings.

261 Instruction, film clip, and affective and compliance ratings together comprised an 262 experimental trial. Each condition was presented twice with four trials in each block. 263 Emotional blocks were followed by 45 -s washout clips a calming film clip (e.g., waves gently 264 rolling back and forth on a beach with a meditative soundtrack), to return affective levels to 265 pre-stimulus baseline. Films were randomized across the WATCH and REGULATE 266 conditions separately for each participant and the presentation order of condition was pseudo267 randomized always starting with a neutral block and ending with a positive block.

268 <nsert Figure 1 here>

\section{'Net' Emotional Effects of Age}

270 The standard method of analysis for behavioural data of emotion regulation tasks is to 271 subtract the raw emotion score (scaled from negative to positive) from the neutral stimulus 272 from raw emotion score from the affective stimulus (positive or negative trials) to create 273 positive and negative reactivity indices. In our task, we challenged affective response after 274 each stimulus on separate positive and negative scales (ranging from 'not at all' to 275 'extremely'). In order to examine the standard response we recreated these scales accounting 276 for the residual emotionality for each scale and regressed them against age to determine age277 related changes in 'net' emotionality. In each participant, we first removed the residual 278 positivity/negativity associated with each scale. To do this, we subtracted the positivity/negativity associated with watching positive/negative films from the positivity/negativity scale associated with watching positive/negative films. We then did the 
same for the Neutral film clips (subtracted negative from positive scales). To gain a 'net'

282 effect score, we then subtracted the Neutral score from either the Positive (for Positive

283 Reactivity) or Negative (for Negative Reactivity) scores. For example;

Net Positive Reactivity $=\left(\right.$ Positive $_{\text {positive }^{\text {Watch }}}-$ Positive $\left._{\text {Watch }}^{\text {negative }}\right)-\left(\right.$ Neutral $_{\text {positive }^{\text {Watch }}}-$ Neutral $\left._{\text {Watch }}{ }_{\text {ngative }}\right)$

Net Negative Reactivity $=\left(\right.$ Negative $^{\text {Watch }}{ }_{\text {negative }}-$ Negative $\left._{\text {pastive }}\right)-\left(\right.$ Neutral $_{\text {Watch }}^{\text {Wegative }}-$ Neutral $\left.^{\text {Watch }}{ }_{\text {positive }}\right)$

Net Negative Regulation $=\left(\right.$ Negative $_{\text {Regulate }}^{\text {negative }}-$ Negative $\left._{\text {positive }^{\text {Reglate }}}\right)-\left(\right.$ Negative $_{\text {Watch }}^{\text {negative }}-$

\section{Demographic, cognitive and mental health measures}

Baseline characteristics collected from the Cam-CAN cohort include age, sex, history of

depression $(\mathrm{y} / \mathrm{n})$ and a self-reported measure of highest level of education obtained, scored

292 from 1 = 'Basic' (e.g., left education before 16), 2 = 'GCSE/O-level' (e.g., left education

293 before 18), 3 = 'A-level' (e.g., left education after 18) and 4 = 'Degree' (e.g., left university

294 after 21 or older). Cognitive control as indexed by fluid intelligence (Duncan, 1995) was measured by the Cattell Culture Fair Test (Scale 2, Form A), administered using pencil-andpaper according to the standard protocol.

\section{MRI data; Source-Based Morphometry (SBM)}

298 For details of the MRI sequences, see (Shafto et al., 2014); for details of the MRI pre299 processing, see (Taylor et al., 2017). Voxel-based morphometry is a univariate method and 300 does not utilize any information about the relationships among voxels. In addition, it will 301 only detect voxels for which a specific predicted effect is present (typically, a mean 302 difference between two groups). In contrast, a multivariate, data-driven approach can provide 303 a way to pool information across different voxels as well as identify unpredicted patterns. 304 The voxels that carry similar information will group to a set of regions. SBM uses 
305 independent component analysis (ICA) to extract maximally spatially independent sources

306 revealing patterns of variation that occur in structural MRI images (Xu et al., 2009).

307 Prior to ICA, we estimated the number of components for extraction using an information308 theoretic approach. First, we uniformly sub-sampled the gray matter images until the 309 estimated entropy rate equalled the entropy rate of an independent and identically distributed 310 (i.i.d.) Gaussian random process of the same variance and data length. Next, we estimated the 311 number of components using the Akaike's Information Criterion (AIC) resulting in 51 312 estimated components.

313 All gray matter images were processed using spatial ICA (Calhoun et al., 2001) as 314 implemented in the GIFT toolbox (http://icatb.sourceforge.net). ICA was performed using a 315 neural network algorithm (infomax) that attempts to minimize the mutual information of the 316 network outputs (Bell and Sejnowski, 1995). Every gray matter image is converted into a 317 one-dimensional vector. The 249 gray matter images of each participant were arrayed into 318 one 249-row subject-by-gray matter data matrix. This matrix was then decomposed into a 319 mixing matrix and a source matrix. The mixing matrix expresses the relationship between 320249 subjects and $k(\mathrm{n}=51)$ components. The rows of the matrix are scores which indicate to 321 what degree that the $k$ components contribute to a given subject. The columns of the matrix 322 indicate how one component contributes to the 249 subjects. In contrast, the source matrix 323 expresses the relationship between the $k$ components and the voxels within the brain. The 324 rows of the matrix indicate how one component contributes to different brain voxels, and the 325 columns of the matrix are scores that indicate how one voxel contributes to each of the 326 components. We used the source matrix for visualization. We reshaped every row of the 327 source matrix back into a 3D image (source map). These source maps were scaled to unit 328 standard deviation (SBM $Z$ map) and threshold at a value of $|Z|>3: 0$. The maps of the sources 329 were then superimposed on the MNI-normalized template brain. 
330 We selected 12 bilaterally represented components which anatomically (Harvard-Oxford 331 Atlas) overlapped with emotion reactivity and regulation related regions taken from the 332 existing functional imaging literature (Phan et al., 2002; Diekhof et al., 2011; Buhle et al., 333 2014; Frank et al., 2014; Kohn et al., 2014); precuneus/posterior cingulate cortex (PCC), 334 superior frontal gyrus (SFG), middle temporal gyrus (MTG), anterior/middle cingulate cortex (A/MCC), middle frontal gyrus (MFG), inferior frontal gyrus (IFG) pars triangularis, IFG pars opercularis, ventral striatum, hippocampus/amygdala complex, medial frontal gyrus, anterior insula and angular gyrus. Data extracted from the mixing matrix for each source were entered into the SEM. Please see Figure 4 and Table 3 for visualization and covariance matrix.

\section{Statistical Analysis}

Analysis of the effects of age was performed by multiple regression within General

342 Linear Models (GLMs) that treated age as a continuous variable modelled by linear and 343 quadratic terms. We focus on effect sizes $\left(\mathrm{R}^{2}\right)$, expressed as the percentage of variance 344 explained by a specific statistical contrast within the GLM, rather than p-values, since the 345 latter become less appropriate for larger samples.

346 Structural Equation Models (SEMs)

347 SEMs were fit using the package Lavaan71 (Rosseel, 2012) in $\mathrm{R}$ version 3.1.2 ( $\mathrm{R}$ 348 Development Core Team, 2011). We used the following guidelines for judging good fit 349 (Schermelleh-Engel et al., 2003): Root Mean Square Error of Approximation (RMSEA) 350 below 0.05 (acceptable: 0.05-0.08) and a Comparative Fit Index (CFI) above 0.97 351 (acceptable: 0.95-0.97). All models were fit using Maximum Likelihood Estimation using 352 robust standard errors, for which we report the Satorra-Bentler (SB) scaled test statistic. P353 values less than .05 were used to judge significance of individual paths. We initially tested a 354 single factor model to establish whether a single general emotionality factor could explain the 
individual difference in affect ratings. We then tested a four-factor measurement model based on theoretically derived notions of emotional reactivity and regulation. Once the measurement model was established, we finally tested a hierarchical model to assess whether

358 the four factors were influence by a single general emotionality factor.

Results

Emotion Reactivity and Regulation Measurement Models

Using Confirmatory Factor Analysis, we tested a series of models which could account for the individual differences in ERRT ratings. A single factor model, with one emotion factor explaining all 8 ERRT ratings ('NEUTRAL WATCH' - Positive and Negative ratings; 'POSITIVE WATCH' - Positive and Negative ratings; 'NEGATIVE WATCH' - Positive and Negative ratings; 'NEGATIVE REGULATE' - Positive and Negative ratings) did not fit the data well (see Table 2 for fit statistics). We therefore explored a four-factor model, with each factor hypothetically representative of the theoretically plausible constructs of emotion reactivity and regulation: 'Negative Regulation', reflecting decreases in negative affectivity in response to negative stimuli and consequently loading negatively on NEGATIVE REGULATE negative ratings and

372 NEGATIVE WATCH negative ratings; 'Positive Regulation', reflecting increased positive 373 affectivity in response to negative stimuli and consequently loading positively on NEGATIVE REGULATE positive ratings and NEGATIVE WATCH positive ratings; Negative Reactivity, reflecting acute increases in negative affectivity and consequently loading on negative ratings across all three WATCH conditions; and Positive Reactivity, loading on the positive ratings from the POSITIVE and NEUTRAL WATCH conditions.

378 This four-factor model fit the data significantly better than the single factor model $\left(\Delta \chi^{2}=\right.$ 
192, $\Delta \mathrm{df}=8, \mathrm{p}=2.2 \mathrm{e}-16$ ), but remained just below the pre-defined threshold for good fit

380 (Table 2).

381 We next investigated the modification indices of the four-factor model to ask whether freeing 382 any parameters would improve model fit. The value of a given modification index (m.i.) is 383 the minimum amount that the chi-square statistic is expected to decrease if the corresponding 384 parameter is freed. This suggested 3 minor modifications to the model : 1) To account for the residual anticorrelation between positive and negative emotion ratings elucidated from watching positive content $(\mathrm{m} . \mathrm{i} .=42.41) ; 2)$ to account for the anticorrelation between positive emotion ratings from the POSITIVE WATCH condition and the latent factor of 388 Negative Reactivity (derived from all negative emotion ratings from the Watch conditions) (m.i. $=24.08) ; 3)$ To account for the residual covariance associated with negative emotion ratings from the NEGATIVE REGULATE condition and positive emotion ratings from the NEGATIVE WATCH condition i.e. the assertion that regulation of negative content is 392 associated with the degree of positivity derived from simply watching negative content (m.i. $393=18.26$ ). With these 3 modifications, the model fit very well (Table 2). Finally, we tested a 394 hierarchical factor model, whereby the four factors of the previous model underlie a single 395 hierarchical factor of general emotionality. This model did not converge and was rejected.

396 Having established a four-factor measurement model, we then explored the significant 397 individual path loadings for each latent factor to refine our interpretation in line with the 398 theoretical and empirical literature. Starting with the positive affect components, our putative 399 Positive Reactivity factor did load significantly and positively, as anticipated, onto the 400 NEUTRAL WATCH positive ratings (0.82) and POSITIVE WATCH positive ratings (1.02) 401 and so we retained the interpretation of this factor as an index of 'Positive Reactivity' i.e. the 402 degree of positivity derived from both neutral and positive content. Our putative 'Positive 403 Regulation' factor loaded positively onto positive scores from both the NEGATIVE 
REGULATE (0.89) and NEGATIVE WATCH (0.77) conditions, representing the degree of

positivity extracted from negative content and thus we also kept our interpretation of this latent factor as a form of 'Positive Regulation'.

In terms of the negative emotion components, both the NEGATIVE REGULATE negative ratings (0.86) and NEGATIVE WATCH negative ratings (0.86) loaded comparably strongly but positively rather than negatively onto the latent factor we initially termed Negative Regulation. A paired t-test on the raw scores revealed no significant difference between negative emotion ratings when either regulating or simply watching negative content $(\mathrm{t}=.057$, $\mathrm{p}=.954)$. This, together with the direction of associations, indicated that this latent factor is better interpreted as a measure of 'Negative Reactivity' to negative content. Finally, the negative ratings from the NEUTRAL WATCH (0.90) and POSITIVE WATCH $(0.58)$ conditions, but importantly not the negative ratings from the NEGATIVE WATCH condition (0.06), showed significant loadings on our original Negative Reactivity factor. With the strongest relationship to the negative rating from the neutral content, and moderate relationship with deriving negativity from positive films, we deemed that this initiallycharacterized Negative Reactivity factor better represents 'Basal Negative Affect', particularly as there was no relationship with negative scores in the NEGATIVE WATCH condition. <Insert Table 2 here>

\section{Effects of Age}

We next included age as a common cause of individual differences in each latent factor which produced an excellent overall model fit (Table 2) with parameters shown in Figure 2. Age had a significant relationship with all four latent factors, with factor strength (i.e. higher affect ratings) increasing with increasing age (Positive Regulation $(\mathrm{F}(1,247)=72.5$ $\mathrm{p}<.0001, \mathrm{r}^{2}=.22 ; 95 \%$ c.i. $\left.=0.14-0.31\right) ;$ Positive Reactivity $\left(\mathrm{F}(1,247)=62.9 \mathrm{p}<.0001 \mathrm{r}^{2}=\right.$ $.20 ; 95 \%$ c.i. $=0.12-0.29) ;$ Basal Negative Affect $\left(\mathrm{F}(1,247)=109.3 \mathrm{p}<.0001, \mathrm{r}^{2}=.30 ; 95 \%\right.$ 
c.i. $=0.22-0.39)$ ), although there was a weaker (though significant) influence on Negative

430 Reactivity compared to the other three factors (Negative Reactivity $(\mathrm{F}(1,247)=8.1 \mathrm{p}=.004$,

$431 \mathrm{r}^{2}=.03 ; 95 \%$ c.i. $\left.=0.00-0.08\right)$. Indeed, this model was better than one in which the age-

432 factor paths were constrained to be equal $\left(\Delta \chi^{2}=38, \Delta \mathrm{df}=3, \mathrm{p}<3.32 \mathrm{e}-08\right)$, suggesting

433 differential effects of age on these emotion factors. This supports our primary hypothesis that

434 the factor constructs of both Positive Reactivity and Positive Regulation increase with age

435 once you disaggregate emotion components by valence.

436 <Insert Figure 2 here>

\section{Elucidating the contribution of cognitive control}

438 In order to explore the contribution of cognitive or executive control, we next introduced our 439 measure of fluid intelligence into the model, along with education level to index potential 440 cohort effects. The model fit remained acceptable (Table 2). As expected, age was 441 significantly negatively associated with education level (-0.21) and fluid intelligence (-0.69), 442 reflecting shifts in UK education accessibility and policy over time. However, importantly 443 neither educational level nor fluid intelligence showed any direct significant effects on our 444 two positive emotion factors - Positive Reactivity and Positive Regulation - indicating that 445 the significant increases in positive emotion processing with age are above and beyond any 446 concomitant decline in fluid intelligence, or cohort effects. The relationship between age and 447 Basal Negative Affect also remained significant. However, the positive influence of age on 448 the Negative Reactivity factor was no longer significant when including fluid intelligence and 449 education in the model suggesting that age-related increases in negative reactivity are a 450 function of age-related declines in cognitive control.

451 Examining the effects of gender and depression

452 To further externally validate the model we next included two variables which have been 453 reported to reliably influence emotion responding - gender, and a history of depression. 
454 Based on the prior literature we anticipated that female gender would be significantly 455 associated with both Positive and Negative Reactivity independent of the effects of age 456 (Kring and Gordon, 1998). We also anticipated that a history of depression would be 457 associated with higher Basal Negative Affect (Kanske et al., 2012) and potentially with higher 458 Negative Reactivity, again independent of age.

459 The model retained its acceptable fit following the inclusion of these variables (Table 2). A 460 history of depression was, as expected, positively associated with Basal Negative Affect 461 (0.16) but no other factors. Being female was significantly associated with both Positive 462 Reactivity (0.21) and Negative Reactivity (0.31) but no other factors. These relationships 463 provide convergent validity for the latent factors in the model. Importantly, the key effects of 464 age on Positive Reactivity and Positive Regulation, as well as on Basal Negative Affect, 465 remained significant beyond the contribution of these additional variables being included in 466 the model (Figure 3). This is important as other age-related effects on affective processing 467 appear to be a function of age-related differences in depression (Murphy et al., 2019).

468 <Insert Figure 3 here>

469 Evaluating the influence of volumetric indices of brain regions involved in emotion 470 reactivity and regulation

471 As expected, each of the GM sources declined linearly with age, though with varying degrees 472 (Figure 4), the Middle Temporal Gyrus (MTG) showed the greatest effect of age $\left(\mathrm{r}^{2}=40 \%\right.$; $47395 \%$ c.i. $=0.32-0.48)$, while the Angular Gyrus showed the least effect of age $\left(r^{2}=4 \%\right.$; $95 \%$ 474 c.i. $=0.01-0.10)$.

475 <Insert Figure 4 here>

$476<$ Insert Table 3 here>

477 We next examined whether there were meaningful relationships between variation in GM in 478 these brain regions and our affectivity factors. Data from the GM sources were included in a 
new SEM as putative causes of the factors. For these models, we retained education, depression and gender in the model but removed fluid intelligence as here we were, in principle, examining the variance associated with neural indices of cognitive control and did not want these to be obscured by including a behavioural index of cognitive control in the model. It is important to stress that significant paths represent unique covariance between the brain variable and latent variable over and above the shared covariance between the other brain variables. Thus, significant paths should not be interpreted as one-to-one regionbehaviour mapping. However, model comparison can be used to test the importance of particular combinations of brain variables (Henson et al., 2016).

Model comparison allows us to test the differential partial contribution of each GMV source to the different latent factors. First, we imposed equality constraints on all brain-behaviour paths to test against the unique contributions of our brain factors. This model failed to converge, suggesting each of the brain-behaviour paths need to be estimated freely and that each has unique variability that explains some of the data. We then tested models which zeroed out each GM source to all emotion factors, to investigate the unique contribution of each region to the emotion factors. Independent models showed zeroing out the effect of the $\operatorname{PCC}(\Delta \chi 2=2, \Delta d f=4, p=0.68), \operatorname{SFG}(\Delta \chi 2=4, \Delta d f=4, p=0.45), \mathrm{A} / \mathrm{MCC}\left(\Delta \chi^{2}=3, \Delta \mathrm{df}=\right.$ $4, \mathrm{p}=0.62), \operatorname{MFG}\left(\Delta \chi^{2}=1, \Delta \mathrm{df}=4, \mathrm{p}=0.88\right)$, pars triangularis $(\Delta \chi 2=5, \Delta \mathrm{df}=4, \mathrm{p}=0.27)$, ventral striatum $(\Delta \chi 2=4, \Delta \mathrm{df}=4, \mathrm{p}=0.44)$, hippocampus/amygdala $\left(\Delta \chi^{2}=6, \Delta \mathrm{df}=4, \mathrm{p}=\right.$ $0.17)$, medial frontal gyrus $(\Delta \chi 2=7, \Delta \mathrm{df}=4, \mathrm{p}=0.12)$, anterior insula $\left(\Delta \chi^{2}=6, \Delta \mathrm{df}=4, \mathrm{p}=\right.$ $0.21)$ and angular gyrus $(\Delta \chi 2=5, \Delta \mathrm{df}=4, \mathrm{p}=0.24)$ did not significantly change model fit. However, separately setting IFG pars opercularis $(\Delta \chi 2=16, \Delta \mathrm{df}=4, \mathrm{p}<0.005)$ and MTG $(\Delta \chi 2=20, \Delta \mathrm{df}=4, \mathrm{p}<0.001)$ paths to zero did significantly reduce model fit, indicating a significant independent partial contribution of these regions to the emotion factors. 
503 Five GM sources showed significant paths to our affective factors. Starting with the positive 504 factors, Positive Reactivity was negatively associated with GM in the IFG pars opercularis (-

505 .26). Positive Regulation was also negatively associated with GM in IFG pars opercularis ($506.24)$ and the MTG (-.42), but positively associated with GM in the hippocampal/amygdala 507 complex (0.19) and angular gyrus (0.16). For the negative emotion factors, Basal Negative 508 Affect was also negatively associated with GM in IFG pars opercularis (-.24) and with GM in 509 the medial frontal gyrus (-.29). There were no significant brain-behaviour relationships 510 between any GM source and the Negative Reactivity factor.

\section{The relationship of age to emotion-related brain-behaviour associations}

We next entered age into the brain-behaviour model connected to each of the 4 513 emotion factors. Model fit remained excellent (Table 2). Critically, mirroring the findings 514 after adjusting for our behavioural index of cognitive control (fluid intelligence), the positive 515 relationship of age with the two components of positive emotion - Positive Regulation and 516 Positive Reactivity - remained significant after the brain variables were introduced indicating 517 that age-related improvements in positive emotion processing are above and beyond any 518 concomitant decline in brain volume in regions associated in the literature with emotion 519 reactivity and regulation. The significant relationship between age and Basal Negative Affect 520 was also preserved (see Figure 5).

521 Three brain-behaviour paths were no longer significant once age was included in the model. 522 The medial FG and IFG pars opercularis were no longer significantly negatively associated with Basal Negative Affect, and the hippocampal/amygdala complex was no longer significantly positively associated with Positive Regulation, suggesting these particular relationships between brain metrics and emotion components are a function of the effects of aging. The remaining specific brain-behaviour pathways remained significant, indicating a 
527 unique contribution of individual differences in the volume of these brain regions to the

528 emotion factors over-and-above the effects of age (Figure 5 and Figure 6).

529 <Insert Figure 5 here>

$530<$ Insert Figure 6 here>

531 'Net' Emotional Effects of Age - Results

532 Applying this approach, the relationship between older age and increased positive affectivity 533 disappeared. The computed 'Net' Positive Reactivity measure was negatively correlated with 534 age $(r=-.188, \mathrm{p}=0.003)$ highlighting the sensitivity of scaling effects in measuring 535 emotional responding. Further, there was no significant correlation between age and the 536 computed 'Net' Negative Reactivity $(r=.071)$ or 'Net' Negative Regulation $(r=-.006)$ measures. This highlights the importance of disaggregating positive and negative affectivity in the modelling in order to elucidate age-related positivity effects.

\section{Discussion}

541

In a large population-representative sample, we show that positive affect in response to emotional and neutral stimuli increases with age, even after controlling for behavioural and neural measures of declining executive control, in line with the 'positivity effect' and the predictions of the SST (Carstensen, 1992, 2006) and ABM (Cacioppo et al., 2011). This was not the case for negative affect generated in response to negative stimuli, although we did find evidence of age-related increases in basal negative affect (based on negative affect ratings to neutral and positive stimuli). Furthermore, we show that emotion-related structural

549 GM sources support and suppress affective responding and that certain brain-behaviour 550 relationships change with age. 
552 A key aspect of the data was the breakdown of the 'net' emotional effect often reported in 553 studies of emotion regulation in older adults (Allard and Kensinger, 2014). Using this 554 approach we were able to separate positive and negative scales in the emotion regulation 555 condition and show that Positive Regulation (deriving positive affect from negative material) 556 significantly increased with age, whereas negative regulation (downregulating negative 557 affect) did not. The data are thus in agreement with evidence of improved emotion regulation 558 with age (Urry and Gross, 2010). Importantly, when using the computed 'net' scores the relationship between older age and increased positive affectivity disappeared. The computed 'net' Positive Reactivity measure was negatively correlated with age, in line with our previous results (Schweizer et al., 2018). This highlights the importance of disaggregating positive and negative affectivity in the modelling in order to elucidate age-related positivity effects.

Additionally, we included structural gray-matter sources derived from independent component analysis of structural MR data to examine brain-behaviour relationships and the influence of age on those relationships. Firstly, we observed decline in all gray matter sources associated with increasing age, in line with previous studies of age-related GMV loss (e.g. (Kalpouzos et al., 2009)). Using these sources, we then tested the diverging predictions of the amygdala-focused $\mathrm{ABM}$ and the frontal-focused cognitive control model at the neural level. We found no evidence in support of the ABM, with model comparison showing no unique contribution of the hippocampal/amygdala complex to any emotion factor and finding that age devalued the contribution of hippocampal/amygdala complex to Positive Regulation.

574 Further to this, we found limited evidence for the cognitive control model, showing the pars 575 opercularis of the IFG have a unique negative influence on Basal Negative Affect and Positive 576 Reactivity as well as Positive Regulation. The IFG is a core emotion regulation brain region 
577 typically engaged when reappraising negative information and is implicated in reducing 578 levels of negative affect (Goldin et al., 2008). However, our data suggest that the structural 579 integrity of the IFG showed a negative relationship with several of our latent factors. One 580 possibility is that the brain-behaviour relationship between the IFG and Positive Regulation 581 factor exerts a dampening effect on the positivity derived from negative stimuli. This is in 582 line with our previous findings using the same stimuli in an imaging version of the task on a 583 separate Cam-CAN sample, where decreased positivity was associated with decreased IFG 584 activation (Schweizer et al., 2018). These effects could feasibly extend to the Positive 585 Reactivity factor, whereby dispositional positivity is dampened as a function of 586 spontaneous/automatic emotion regulation/control. Finally, we showed that age devalued the negative influence of the IFG and Medial FG on Basal Negative Affect, which speculatively may account for the unexpected observed increases in this factor score with age. Overall, and importantly in the context of the predictions of SST, age-related increases in Positive

590 Regulation and Positive Reactivity remained significant over and above the negative 591 influence of the neural measures.

592 In sum, this study used a population-derived sample from across the life span to investigate 593 positive and negative affective responses to ecologically valid stimuli in order to explore the 594 emotion-aging paradox. We found evidence broadly in line with the predictions of the SST, 595 finding that positive responding increased with increasing age. Furthermore, these changes 596 were related to the structural integrity of several neural regions typically associated with 597 emotion regulation. We provide neural evidence against the Aging Brain Model, instead 598 showing that age devalues the contribution of the hippocampal/amygdala complex to Positive 599 Regulation. Moreover, several of these brain-behaviour relationships remain unaffected by 600 age and may therefore constitute empirically derived neural markers to disentangle the 601 paradox of increased well-being in old age. 
604

605

606

607

608

609

610

611

612

613

614

615

616

617

618

619

620

621

622

623

624

625

626

627

628

629

630

631

632

633

634

635

636

637

638

639

640

641

642

643

644

645

646

647

648

\section{References}

Allard ES, Kensinger EA (2014) Age-related differences in functional connectivity during cognitive emotion regulation. J Gerontol B Psychol Sci Soc Sci 69:852-860.

Allen JS, Bruss J, Damasio H (2005) The aging brain: the cognitive reserve hypothesis and hominid evolution. Am J Hum Biol 17:673-689.

Bell AJ, Sejnowski TJ (1995) An information-maximization approach to blind separation and blind deconvolution. Neural Comput 7:1129-1159.

Birditt KS, Fingerman KL, Almeida DM (2005) Age differences in exposure and reactions to interpersonal tensions: a daily diary study. Psychol Aging 20:330-340.

Brabec J, Rulseh A, Hoyt B, Vizek M, Horinek D, Hort J, Petrovicky P (2010) Volumetry of the human amygdala - an anatomical study. Psychiatry Res 182:67-72.

Braunstein LM, Gross JJ, Ochsner KN (2017) Explicit and implicit emotion regulation: a multi-level framework. Social cognitive and affective neuroscience 12:1545-1557.

Braver TS, Barch DM (2002) A theory of cognitive control, aging cognition, and neuromodulation. Neurosci Biobehav Rev 26:809-817.

Buhle JT, Silvers JA, Wager TD, Lopez R, Onyemekwu C, Kober H, Weber J, Ochsner KN (2014) Cognitive reappraisal of emotion: a meta-analysis of human neuroimaging studies. Cereb Cortex 24:2981-2990.

Burr DA, Castrellon JJ, Zald DH, Samanez-Larkin GR (2020) Emotion dynamics across adulthood in everyday life: Older adults are more emotionally stable and better at regulating desires. Emotion.

Bush G, Luu P, Posner MI (2000) Cognitive and emotional influences in anterior cingulate cortex. Trends in cognitive sciences 4:215-222.

Cacioppo JT, Berntson GG, Bechara A, Tranel D, Hawkley LC (2011) Could an aging brain contribute to subjective well-being? The value added by a social neuroscience perspective.

Calhoun VD, Adali T, Pearlson GD, Pekar JJ (2001) Spatial and temporal independent component analysis of functional MRI data containing a pair of task-related waveforms. Hum Brain Mapp 13:43-53.

Carstensen LL (1992) Motivation for social contact across the life span: a theory of socioemotional selectivity. Nebr Symp Motiv 40:209-254.

Carstensen LL (2006) The influence of a sense of time on human development. Science 312:19131915.

Carstensen LL, Pasupathi M, Mayr U, Nesselroade JR (2000) Emotional experience in everyday life across the adult life span. J Pers Soc Psychol 79:644-655.

Carstensen LL, Turan B, Scheibe S, Ram N, Ersner-Hershfield H, Samanez-Larkin GR, Brooks KP, Nesselroade JR (2011) Emotional experience improves with age: evidence based on over 10 years of experience sampling. Psychol Aging 26:21-33.

Charles ST (2010) Strength and Vulnerability Integration: A Model of Emotional Well-Being Across Adulthood. Psychological Bulletin 136:1068-1091.

Charles ST, Mather M, Carstensen LL (2003) Aging and emotional memory: the forgettable nature of negative images for older adults. J Exp Psychol Gen 132:310-324.

Diekhof EK, Geier K, Falkai P, Gruber O (2011) Fear is only as deep as the mind allows: a coordinatebased meta-analysis of neuroimaging studies on the regulation of negative affect. Neuroimage 58:275-285.

Duncan J (1995) Attention, intelligence, and the frontal lobes. 
Fjell AM, Walhovd KB, Fennema-Notestine C, McEvoy LK, Hagler DJ, Holland D, Brewer JB, Dale AM (2009a) One-year brain atrophy evident in healthy aging. J Neurosci 29:15223-15231.

Fjell AM, Westlye LT, Amlien I, Espeseth T, Reinvang I, Raz N, Agartz I, Salat DH, Greve DN, Fischl B, Dale AM, Walhovd KB (2009b) High consistency of regional cortical thinning in aging across multiple samples. Cereb Cortex 19:2001-2012.

Frank DW, Dewitt M, Hudgens-Haney M, Schaeffer DJ, Ball BH, Schwarz NF, Hussein AA, Smart LM, Sabatinelli $D$ (2014) Emotion regulation: quantitative meta-analysis of functional activation and deactivation. Neurosci Biobehav Rev 45:202-211.

Goldin PR, McRae K, Ramel W, Gross JJ (2008) The neural bases of emotion regulation: reappraisal and suppression of negative emotion. Biol Psychiatry 63:577-586.

Henson RN et al. (2016) Multiple determinants of lifespan memory differences. Scientific Reports 6:32527.

John OP, Gross JJ (2004) Healthy and unhealthy emotion regulation: Personality processes, individual differences, and life span development. Journal of Personality 72:1301-1333.

Kalpouzos G, Chetelat G, Baron JC, Landeau B, Mevel K, Godeau C, Barre L, Constans JM, Viader F, Eustache $F$, Desgranges B (2009) Voxel-based mapping of brain gray matter volume and glucose metabolism profiles in normal aging. Neurobiol Aging 30:112-124.

Kanske P, Heissler J, Schonfelder S, Wessa M (2012) Neural correlates of emotion regulation deficits in remitted depression: the influence of regulation strategy, habitual regulation use, and emotional valence. Neuroimage 61:686-693.

Kennedy Q, Mather M, Carstensen LL (2004) The role of motivation in the age-related positivity effect in autobiographical memory. Psychol Sci 15:208-214.

Kievit RA, van Rooijen H, Wicherts JM, Waldorp L, Kan KJ, Scholte HS, Borsboom D (2012) Intelligence and the brain: A model-based approach. Cogn Neurosci 3:89-97.

Kohn N, Eickhoff SB, Scheller M, Laird AR, Fox PT, Habel U (2014) Neural network of cognitive emotion regulation--an ALE meta-analysis and MACM analysis. Neuroimage 87:345-355.

Kring AM, Gordon AH (1998) Sex differences in emotion: expression, experience, and physiology. J Pers Soc Psychol 74:686-703.

Labouvie-Vief G (2003) Dynamic Integration:Affect, Cognition, and the Self in Adulthood. Current Directions in Psychological Science 12:201-206.

Livingstone KM, Isaacowitz DM (2019) Age Similarities and Differences in Spontaneous Use of Emotion Regulation Tactics Across Five Laboratory Tasks. Journal of Experimental Psychology-General 148:1972-1992.

Martins B, Sheppes G, Gross JJ, Mather M (2018) Age Differences in Emotion Regulation Choice: Older Adults Use Distraction Less Than Younger Adults in High-Intensity Positive Contexts. J Gerontol B Psychol Sci Soc Sci 73:603-611.

Mather M, Carstensen LL (2005) Aging and motivated cognition: the positivity effect in attention and memory. Trends Cogn Sci 9:496-502.

Mather M, Canli T, English T, Whitfield S, Wais P, Ochsner K, Gabrieli JD, Carstensen LL (2004) Amygdala responses to emotionally valenced stimuli in older and younger adults. Psychol Sci 15:259-263.

Murphy J, Millgate E, Geary H, Catmur C, Bird G (2019) No effect of age on emotion recognition after accounting for cognitive factors and depression. Quarterly Journal of Experimental Psychology 72:2690-2704.

Ochsner KN, Gross JJ (2005) The cognitive control of emotion. Trends Cogn Sci 9:242-249.

ONS (2016) Measuring National Well-being: Happiness.

Opitz PC, Lee IA, Gross JJ, Urry HL (2014) Fluid cognitive ability is a resource for successful emotion regulation in older and younger adults. Front Psychol 5:609.

Paulus MP, Stein MB, Craske MG, Bookheimer S, Taylor CT, Simmons AN, Sidhu N, Young KS, Fan BY (2017) Latent variable analysis of positive and negative valence processing focused on 
symptom and behavioral units of analysis in mood and anxiety disorders. Journal of affective disorders 216:17-29.

Phan KL, Wager T, Taylor SF, Liberzon I (2002) Functional neuroanatomy of emotion: a meta-analysis of emotion activation studies in PET and fMRI. Neuroimage 16:331-348.

Phillips LH, Henry JD, Hosie JA, Milne AB (2008) Effective regulation of the experience and expression of negative affect in old age. J Gerontol B-Psychol 63:P138-P145.

Quirk GJ, Beer JS (2006) Prefrontal involvement in the regulation of emotion: convergence of rat and human studies. Curr Opin Neurobiol 16:723-727.

Rosseel Y (2012) lavaan: An R Package for Structural Equation Modeling. 2012 48:36.

Schermelleh-Engel K, Moosbrugger H, Müller H (2003) Evaluating the Fit of Structural Equation Models: Tests of Significance and Descriptive Goodness-of-Fit Measures. Methods of Psychological Research 8:23-74.

Schweizer S, Grahn J, Hampshire A, Mobbs D, Dalgleish T (2013) Training the emotional brain: improving affective control through emotional working memory training. J Neurosci 33:5301-5311.

Schweizer S, Walsh ND, Stretton J, Dunn VJ, Goodyer IM, Dalgleish T (2016) Enhanced emotion regulation capacity and its neural substrates in those exposed to moderate childhood adversity. Soc Cogn Affect Neurosci 11:272-281.

Schweizer S, J. S, van Belle J, Price D, Calder AJ, T. D (2018) Age-related decline in positive emotional reactivity and emotion regulation in a population-derived cohort. PsyArXiv Preprints.

Shafto MA, Tyler LK, Dixon M, Taylor JR, Rowe JB, Cusack R, Calder AJ, Marslen-Wilson WD, Duncan J, Dalgleish T, Henson RN, Brayne C, Matthews FE, Cam CAN (2014) The Cambridge Centre for Ageing and Neuroscience (Cam-CAN) study protocol: a cross-sectional, lifespan, multidisciplinary examination of healthy cognitive ageing. BMC Neurol 14:204.

Sims T, Hogan C, Carstensen L (2015) Selectivity as an Emotion Regulation Strategy: Lessons from Older Adults. Curr Opin Psychol 3:80-84.

Taylor JR, Williams N, Cusack R, Auer T, Shafto MA, Dixon M, Tyler LK, Cam C, Henson RN (2017) The Cambridge Centre for Ageing and Neuroscience (Cam-CAN) data repository: Structural and functional MRI, MEG, and cognitive data from a cross-sectional adult lifespan sample. Neuroimage 144:262-269.

Urry HL, Gross JJ (2010) Emotion Regulation in Older Age. Current Directions in Psychological Science 19:352-357.

Viinikainen M, Jaaskelainen IR, Alexandrov Y, Balk MH, Autti T, Sams M (2010) Nonlinear Relationship Between Emotional Valence and Brain Activity: Evidence of Separate Negative and Positive Valence Dimensions. Human Brain Mapping 31:1030-1040.

Winecoff A, LaBar KS, Madden DJ, Cabeza R, Huettel SA (2011) Cognitive and neural contributors to emotion regulation in aging. Social cognitive and affective neuroscience 6:165-176.

Winecoff A, Clithero JA, Carter RM, Bergman SR, Wang L, Huettel SA (2013) Ventromedial prefrontal cortex encodes emotional value. J Neurosci 33:11032-11039.

Xu L, Groth KM, Pearlson G, Schretlen DJ, Calhoun VD (2009) Source-based morphometry: The use of independent component analysis to identify gray matter differences with application to schizophrenia. Human brain mapping 30:711-724. 
$759 \quad$ Figure Legends

761 Figure 1. A sample trial of the Emotion Reactivity and Regulation Task where 762 participants viewed a set of negative, neutral or positive 30-second film clips. In the 763 'WATCH' condition, participants were asked to simply watch the films and allow their 764 emotions to arise naturally. In the 'REGULATE' condition (the example shown in the 765 figure), participants were asked to reappraise their emotions to a negative film by 766 changing the way they thought about the film's content. After each film clip, 767 participants rated how the positive and negative affect that they felt during the film on 768 two valence scale, as well as their compliance with the task instructions. 
784 Figure 2. Modified four-factor measurement model and the effects of age. Black paths 785 indicate positive associations, grey paths indicate negative associations, and dashed lines 786 indicate non-significant associations. 
809 Figure 3. SEM of Age and Emotion including cognitive control (indexed by fluid IQ),

810 education, gender and depression measures. Age remained significantly positively 811 associated with 3 emotion factors when accounting for this additional information. 812 Positive Reactivity and Basal Negative Affect and Positive Regulation all increased with 813 increasing age. Black paths indicate positive associations, grey paths indicate negative 814 associations, and dashed lines indicate non-significant associations. Dep = Depression; 815 Edu = Educational level; $\mathbf{I Q}=$ Intelligence Quotient. Coefficient weights have been 816 excluded for clarity (see main text). 
834 Figure 4. Source-Based Morphometry sources relationship to age. Each show decline

835 linearly with age. Effect size is shown as $\mathbf{r}^{2}$. PrC/PCC $=$ Precuneus/Posterior Cingulate 836 Cortex; MTG = Middle Temporal Gyrus; MFG = Middle Frontal Gyrus; VS = Ventral 837 Striatum; MedFG $=$ Medial Frontal Gyrus; IFG Op $=$ Inferior Frontal Gyrus 838 Operculum; $\mathbf{S F G}=$ Superior Frontal Gyrus; $\mathbf{A} / \mathbf{M C C}=$ Anterior $/$ Middle Cingulate 839 Gyrus; IFG PT = Inferior Frontal Gyrus Pars Triangularis; Hc/Amyg = Hippocampal 840 Complex/Amygdala; AI = Anterior Insula; AG = Angular Gyrus. 
859 Figure 5. Brain-Behaviour model with age included. 3 paths no longer reach 860 significance; pars opercularis and medial frontal gyrus to Basal Negative Affect, and 861 hippocampal/amygdala complex to Positive Regulation (dashed lines). For clarity, only 862 significant/changed paths are shown. Black paths indicate positive associations, grey 863 paths indicate negative associations, and dashed lines indicate non-significant 864 associations. For full model fit, see Table 2. Dep = Depression; Edu = Educational level. 865 IFG_Op = Inferior Frontal Gyrus Pars Opercularis; MedFG = Medial Frontal Gyrus; 866 HC/A = Hippocampal/Amygdala Complex; MTG = Middle Temporal Gyrus; AG = 867 Angular Gyrus. Coefficient weights have been excluded for clarity (see main text). 
884 Figure 6. Scatterplots of the brain-behaviour pathways in the full model. Pos Reg =

885 Positive Regulation; Basal Neg = Basal Negative Affect; Pos Reac = Positive Reactivity;

886 IFG Op = Inferior Frontal Gyrus Pars Opercularis; MedFG = Medial Frontal Gyrus;

887 HC/A = Hippocampal/Amygdala Complex; MTG = Middle Temporal Gyrus; AG = 888 Angular Gyrus. 
898

899

\begin{tabular}{lllllllll} 
Decade & 1 & 2 & 3 & 4 & 5 & 6 & 7 \\
\hline \hline
\end{tabular}

900

901

902

903

904

905

906

907

908

909

910

911

912

913

914

915

916

917

918

919

920

921

922

923

Table 1. Sample demographics 


\begin{tabular}{llllllll}
\hline \hline$n$ & 27 & 38 & 44 & 36 & 40 & 39 & 25 \\
\hline \hline Age range; $M$ & $18-28 ;$ & $29-38 ;$ & $39-48 ;$ & $49-58 ;$ & $59-68 ;$ & $69-88 ;$ & $79-88 ;$ \\
$(s d)$ & $24.1(3.6)$ & 33.8 & 44.6 & 53.7 & 64.1 & 73.4 & 82.3 \\
& $(2.6)$ & $(2.9)$ & $(2.9)$ & $(2.7)$ & $(3.1)$ & $(2.8)$ \\
\hline \hline Female $n(\%)$ & $16(59)$ & $19(50)$ & $21(48)$ & $21(58)$ & $19(47)$ & $22(56)$ & $13(52)$ \\
\hline \hline
\end{tabular}

Education $n$

$(\%)$

\begin{tabular}{llllllll}
\hline \hline None & & $1(3)$ & $3(7)$ & $1(3)$ & $3(7)$ & $5(13)$ & $4(16)$ \\
\hline \hline GCSE & $5(18.5)$ & $3(8)$ & $7(16)$ & $6(17)$ & $13(33)$ & $9(23)$ & $5(20)$ \\
\hline \hline A-level & $5(18.5)$ & $5(13)$ & & $9(25)$ & $4(10)$ & $4(10)$ & $4(16)$ \\
\hline $\begin{array}{l}\text { University } \\
\text { degree }\end{array}$ & $17(63)$ & $29(76)$ & $34(77)$ & $20(55)$ & $20(50)$ & $21(54)$ & $12(48)$ \\
\hline $\begin{array}{l}\text { Fluid } \\
\begin{array}{l}\text { ntelligence } M \\
(s d)\end{array}\end{array}$ & $37.3(4.7)$ & $\begin{array}{l}37.5 \\
(3.6)\end{array}$ & $\begin{array}{l}35.8 \\
(3.7)\end{array}$ & $\begin{array}{l}33.4 \\
(4.2)\end{array}$ & $\begin{array}{l}30.9 \\
(4.7)\end{array}$ & $\begin{array}{l}27.7 \\
(5.7)\end{array}$ & $\begin{array}{l}24.9 \\
(3.5)\end{array}$ \\
\hline
\end{tabular}

Table 2. Fits of the main SEMs tested.

\begin{tabular}{|l|l|l|l|l|l|l|}
\hline Model & $\chi^{2}$ & df & RMSEA & CFI & SB & AIC \\
\hline Single Factor & 305 & 20 & 0.24 & 0.69 & 1.40 & 5084 \\
\hline
\end{tabular}




\begin{tabular}{|l|l|l|l|l|l|l|}
\hline Hierarchical Factor & DNC & DNC & DNC & DNC & DNC & DNC \\
\hline Four Factor & 88 & 12 & 0.16 & 0.92 & 1.22 & 4781 \\
\hline Four Factor Modified & 11 & 9 & 0.034 & 0.99 & 1.25 & 4694 \\
\hline Four Factor Modified with Age & 17 & 13 & 0.038 & 0.99 & 1.30 & 6747 \\
\hline Four Factor with Age, Education \& IQ & 52 & 22 & 0.075 & 0.97 & 1.20 & 8007 \\
\hline $\begin{array}{l}\text { Four Factor with Age, Education \& } \\
\text { IQ* }\end{array}$ & 65 & 34 & 0.061 & 0.97 & 1.11 & 9397 \\
\hline Four Factor with GM \& Education* & 79 & 69 & 0.024 & 0.99 & 1.01 & 13550 \\
\hline Four Factor with GM \& Age* & 93 & 87 & 0.017 & 0.99 & 1.02 & 15469 \\
\hline
\end{tabular}

Approximation; CFI = Comparative Fit Index; SB $=$ Satorra-Bentler Scaled test

statistic; AIC = Akaikes Information Criterion; * = these models additionally contained

Gender and Depression variables (affecting all latent factors). Note that the $\chi 2$ reported

942 is the Satorra-Bentler scaled $\chi 2$, with the scaling factor reported as SB. 
Table 3. Correlation Matrix of Source-Based Morphometry Sources.

\begin{tabular}{|c|c|c|c|c|c|c|c|c|c|c|c|c|}
\hline \multicolumn{13}{|l|}{ Correlations } \\
\hline & & $\begin{array}{l}\text { Precuneus/Po } \\
\text { sterior } \\
\text { Cingulate } \\
\text { Cortex }\end{array}$ & $\begin{array}{l}\text { Super } \\
\text { ior } \\
\text { Front } \\
\text { al } \\
\text { Gyru } \\
\text { s } \\
\end{array}$ & \begin{tabular}{|l} 
Middl \\
e \\
Temp \\
oral \\
Gyrus
\end{tabular} & $\begin{array}{l}\text { Anterior/M } \\
\text { iddle } \\
\text { Cingulate }\end{array}$ & $\begin{array}{l}\text { Mid } \\
\text { dle } \\
\text { Fron } \\
\text { tal } \\
\text { Gyr } \\
\text { us } \\
\end{array}$ & $\begin{array}{l}\text { Inferior } \\
\text { Frontal } \\
\text { Gyrus; } \\
\text { Pars } \\
\text { Triangu } \\
\text { laris }\end{array}$ & $\begin{array}{l}\text { Ventr } \\
\text { al } \\
\text { Striat } \\
\text { um }\end{array}$ & $\begin{array}{l}\text { Hippocampal/A } \\
\text { mgydala } \\
\text { Complex }\end{array}$ & $\begin{array}{l}\text { Med } \\
\text { ial } \\
\text { Fron } \\
\text { tal } \\
\text { Gyr } \\
\text { us } \\
\end{array}$ & $\begin{array}{l}\text { Anter } \\
\text { ior } \\
\text { Insul } \\
\text { a }\end{array}$ & \begin{tabular}{|l} 
Inferior \\
Frontal \\
Gyrus, \\
Opercu \\
lum
\end{tabular} \\
\hline \multirow[t]{3}{*}{$\begin{array}{l}\text { Superior Frontal } \\
\text { Gyrus }\end{array}$} & $\begin{array}{l}\text { Pearson } \\
\text { Correla } \\
\text { tion }\end{array}$ & $.371^{* * *}$ & & & & & & & & & & \\
\hline & \begin{tabular}{|l|}
$\begin{array}{l}\text { Sig. (2- } \\
\text { tailed) }\end{array}$ \\
\end{tabular} & 0.000 & & & & & & & & & & \\
\hline & $\mathrm{N}$ & 249 & & & & & & & & & & \\
\hline \multirow[t]{3}{*}{$\begin{array}{l}\text { Middle } \\
\text { Temporal Gyrus }\end{array}$} & $\begin{array}{l}\text { Pearson } \\
\text { Correla } \\
\text { tion } \\
\end{array}$ & $.620^{* * *}$ & $.381^{*}$ & & & & & & & & & \\
\hline & \begin{tabular}{|l|}
$\begin{array}{l}\text { Sig. (2- } \\
\text { tailed) }\end{array}$ \\
\end{tabular} & 0.000 & 0.000 & & & & & & & & & \\
\hline & $\mathrm{N}$ & 249 & 249 & & & & & & & & & \\
\hline \multirow[t]{3}{*}{$\begin{array}{l}\text { Anterior/Middle } \\
\text { Cingulate }\end{array}$} & $\begin{array}{l}\text { Pearson } \\
\text { Correla } \\
\text { tion } \\
\end{array}$ & $.229^{* * *}$ & $.141^{*}$ & $.338^{* *}$ & & & & & & & & \\
\hline & $\begin{array}{l}\text { Sig. (2- } \\
\text { tailed) }\end{array}$ & 0.000 & 0.027 & 0.000 & & & & & & & & \\
\hline & $\mathrm{N}$ & 249 & 249 & 249 & & & & & & & & \\
\hline $\begin{array}{l}\text { Middle Frontal } \\
\text { Gyrus }\end{array}$ & $\begin{array}{l}\text { Pearson } \\
\text { Correla } \\
\text { tion }\end{array}$ & $.518^{* * *}$ & $.590^{*}$ & $.502^{* \% *}$ & $.244^{* * * *}$ & & & & & & & \\
\hline
\end{tabular}




\begin{tabular}{|c|c|c|c|c|c|c|c|c|c|c|c|c|}
\hline & $\begin{array}{l}\text { Sig. (2- } \\
\text { tailed) }\end{array}$ & 0.000 & 0.000 & 0.000 & 0.000 & & & & & & & \\
\hline & $\mathrm{N}$ & 249 & 249 & 249 & 249 & & & & & & & \\
\hline \multirow[t]{3}{*}{$\begin{array}{l}\text { Inferior Frontal } \\
\text { Gyrus; Pars } \\
\text { Triangularis }\end{array}$} & $\begin{array}{l}\text { Pearson } \\
\text { Correla } \\
\text { tion }\end{array}$ & $.564^{* * *}$ & $.483^{*}$ & $.564^{* * \%}$ & $.298^{* * *}$ & .577 & & & & & & \\
\hline & \begin{tabular}{|l|} 
Sig. (2- \\
tailed)
\end{tabular} & 0.000 & 0.000 & 0.000 & 0.000 & $\begin{array}{l}0.00 \\
0\end{array}$ & & & & & & \\
\hline & $\mathrm{N}$ & 249 & 249 & 249 & 249 & 249 & & & & & & \\
\hline \multirow[t]{3}{*}{ Ventral Striatum } & $\begin{array}{l}\text { Pearson } \\
\text { Correla } \\
\text { tion }\end{array}$ & $.563^{* * *}$ & $.457^{*}$ & $.579^{* * 2}$ & $.264^{* * *}$ & .532 & $.536^{* * *}$ & & & & & \\
\hline & \begin{tabular}{|l|}
$\begin{array}{l}\text { Sig. (2- } \\
\text { tailed) }\end{array}$ \\
\end{tabular} & 0.000 & 0.000 & 0.000 & 0.000 & $\begin{array}{l}0.00 \\
0\end{array}$ & 0.000 & & & & & \\
\hline & $\mathrm{N}$ & 249 & 249 & 249 & 249 & 249 & 249 & & & & & \\
\hline \multirow[t]{3}{*}{$\begin{array}{l}\text { Hippocampal/A } \\
\text { mygdala } \\
\text { Complex }\end{array}$} & $\begin{array}{l}\text { Pearson } \\
\text { Correla } \\
\text { tion } \\
\end{array}$ & $.569^{\text {*** }}$ & $.306^{*}$ & $.659^{* 29}$ & $.322^{* * *}$ & $\begin{array}{l}.462 \\
* * * \\
\text {. }\end{array}$ & $.523^{* * *}$ & $.531^{*}$ & & & & \\
\hline & $\begin{array}{l}\text { Sig. (2- } \\
\text { tailed) }\end{array}$ & 0.000 & 0.000 & 0.000 & 0.000 & $\begin{array}{l}0.00 \\
0\end{array}$ & 0.000 & 0.000 & & & & \\
\hline & $\mathrm{N}$ & 249 & 249 & 249 & 249 & 249 & 249 & 249 & & & & \\
\hline \multirow[t]{3}{*}{$\begin{array}{l}\text { Medial Frontal } \\
\text { Gyrus }\end{array}$} & $\begin{array}{l}\text { Pearson } \\
\text { Correla } \\
\text { tion }\end{array}$ & $.647^{\text {*** }}$ & $.453^{*}$ & $.706^{\text {**\% }}$ & $.253^{\text {*** }}$ & .634 & $.667^{* * *}$ & $.624^{*}$ & $.615^{* *}$ & & & \\
\hline & \begin{tabular}{|l|} 
Sig. (2- \\
tailed)
\end{tabular} & 0.000 & 0.000 & 0.000 & 0.000 & $\begin{array}{l}0.00 \\
0\end{array}$ & 0.000 & 0.000 & 0.000 & & & \\
\hline & $\mathrm{N}$ & 249 & 249 & 249 & 249 & 249 & 249 & 249 & 249 & & & \\
\hline \multirow[t]{2}{*}{ Anterior Insula } & $\begin{array}{l}\text { Pearson } \\
\text { Correla } \\
\text { tion } \\
\end{array}$ & $.584^{\text {*.* }}$ & $.422^{*}$ & $.623^{* * *}$ & $.358^{\text {**F }}$ & .495 & $.618^{* * *}$ & $.601^{*}$ & $.569^{* * *}$ & .688 & & \\
\hline & Sig. (2- & 0.000 & 0.000 & 0.000 & 0.000 & 0.00 & 0.000 & 0.000 & 0.000 & 0.00 & & \\
\hline
\end{tabular}




\begin{tabular}{|c|c|c|c|c|c|c|c|c|c|c|c|c|}
\hline & \begin{tabular}{|l|} 
tailed) \\
\end{tabular} & & & & & 0 & & & & 0 & & \\
\hline & $\mathrm{N}$ & \begin{tabular}{|l|}
249 \\
\end{tabular} & 249 & 249 & \begin{tabular}{|l|}
249 \\
\end{tabular} & \begin{tabular}{|l|}
249 \\
\end{tabular} & 249 & 249 & 249 & 249 & & \\
\hline \multirow[t]{3}{*}{$\begin{array}{l}\text { Inferior Frontal } \\
\text { Gyrus, } \\
\text { Operculum }\end{array}$} & $\begin{array}{l}\text { Pearson } \\
\text { Correla } \\
\text { tion }\end{array}$ & $.494^{* *}$ & $.291^{*}$ & $.578^{* * *}$ & $.246^{* * *}$ & \begin{tabular}{|l|l|}
.442 \\
$* * *$
\end{tabular} & $.470^{* * *}$ & $.391^{*}$ & $.503^{* *}$ & \begin{tabular}{|l}
597 \\
$* * *$
\end{tabular} & $.523^{*}$ & \\
\hline & \begin{tabular}{|l|} 
Sig. (2- \\
tailed) \\
\end{tabular} & 0.000 & 0.000 & 0.000 & 0.000 & \begin{tabular}{|l|}
0.00 \\
0 \\
\end{tabular} & 0.000 & 0.000 & 0.000 & \begin{tabular}{|l|}
0.00 \\
0 \\
\end{tabular} & 0.000 & \\
\hline & $\mathrm{N}$ & 249 & 249 & 249 & 249 & 249 & 249 & 249 & 249 & 249 & \begin{tabular}{|l|}
249 \\
\end{tabular} & \\
\hline \multirow[t]{3}{*}{ Angular Gyrus } & $\begin{array}{l}\text { Pearson } \\
\text { Correla } \\
\text { tion } \\
\end{array}$ & $.284^{* *}$ & 0.074 & $.327^{* *}$ & 0.094 & .189 & $.188^{* *}$ & $.161^{*}$ & $.280^{* *}$ & .284 & $.230^{*}$ & $.186^{* *}$ \\
\hline & $\begin{array}{l}\text { Sig. (2- } \\
\text { tailed) }\end{array}$ & 0.000 & 0.246 & 0.000 & $\mid 0.141$ & $\begin{array}{l}0.00 \\
3 \\
\end{array}$ & 0.003 & 0.011 & 0.000 & \begin{tabular}{|l|}
0.00 \\
0 \\
\end{tabular} & 0.000 & 0.003 \\
\hline & $\mathrm{N}$ & 249 & 249 & 249 & 249 & 249 & 249 & 249 & 249 & 249 & 249 & 249 \\
\hline
\end{tabular}



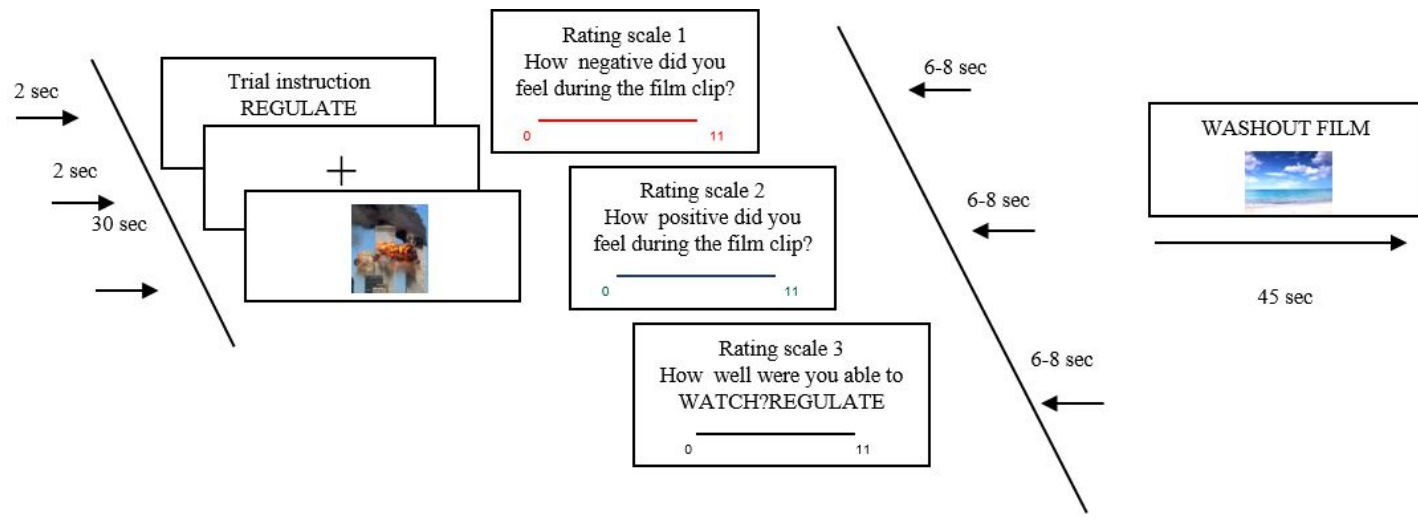

REGULATE

$2 \mathrm{sec}$ 


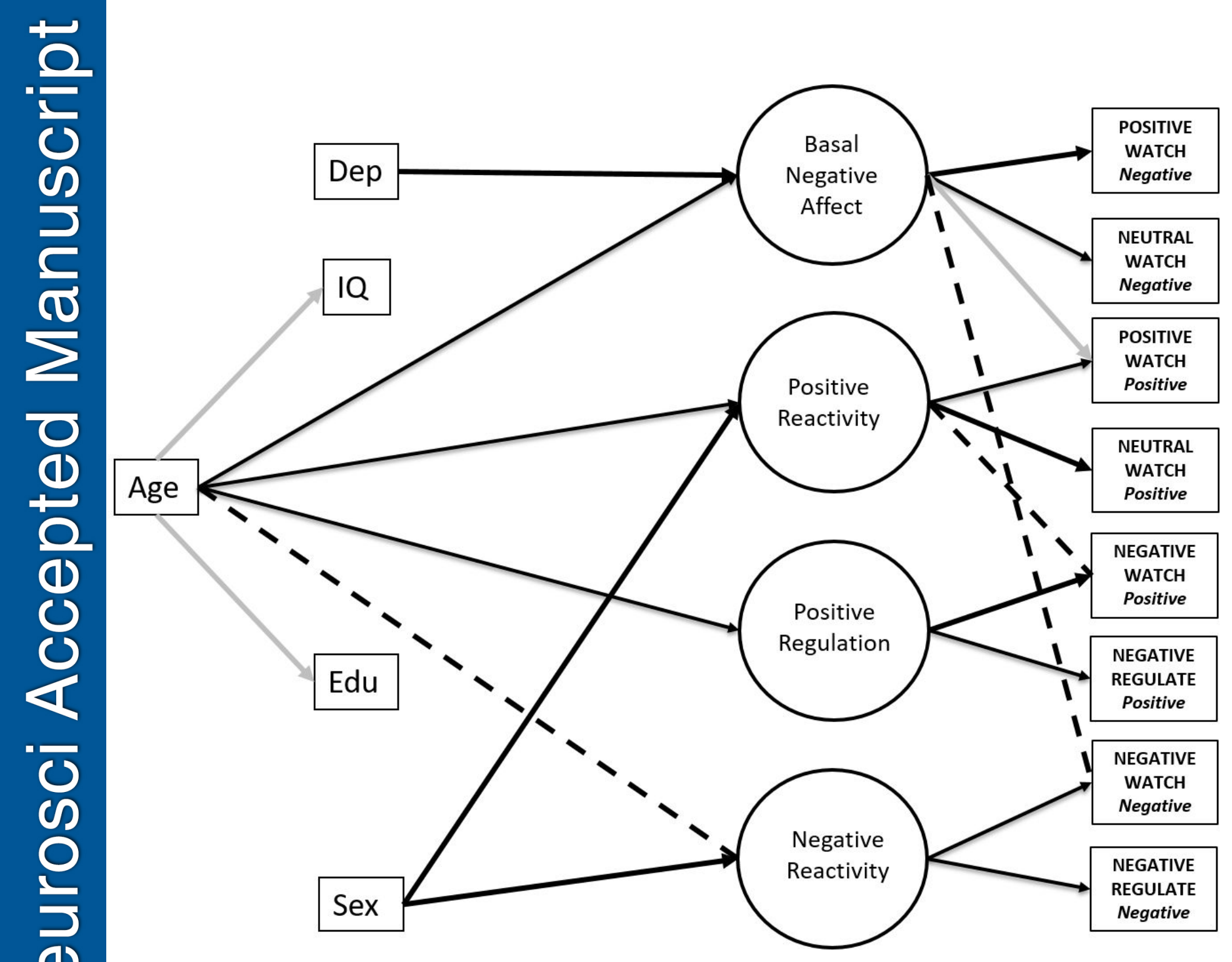



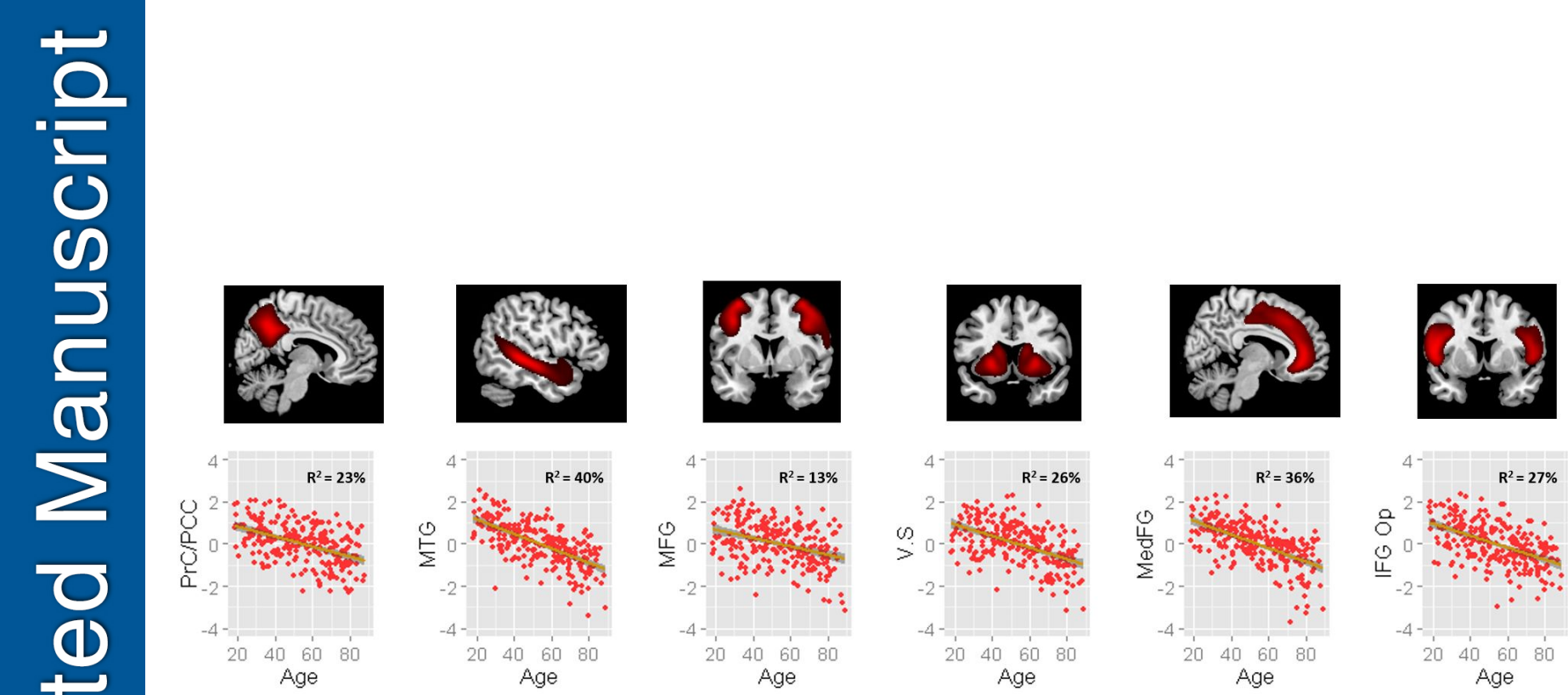

흥
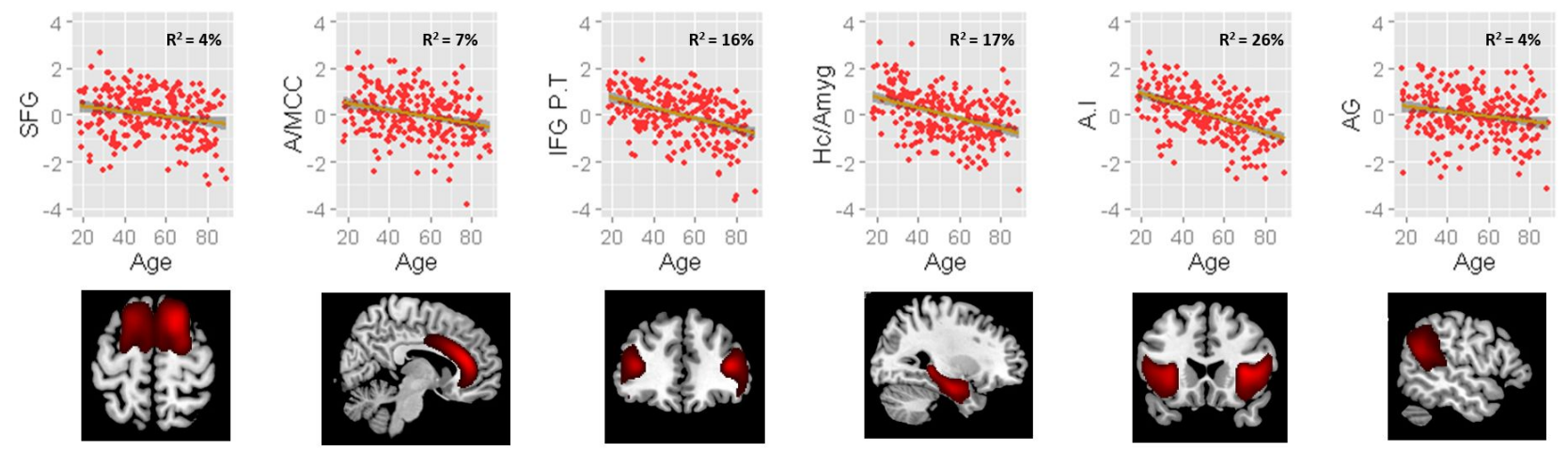

0

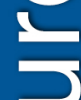

(1) 

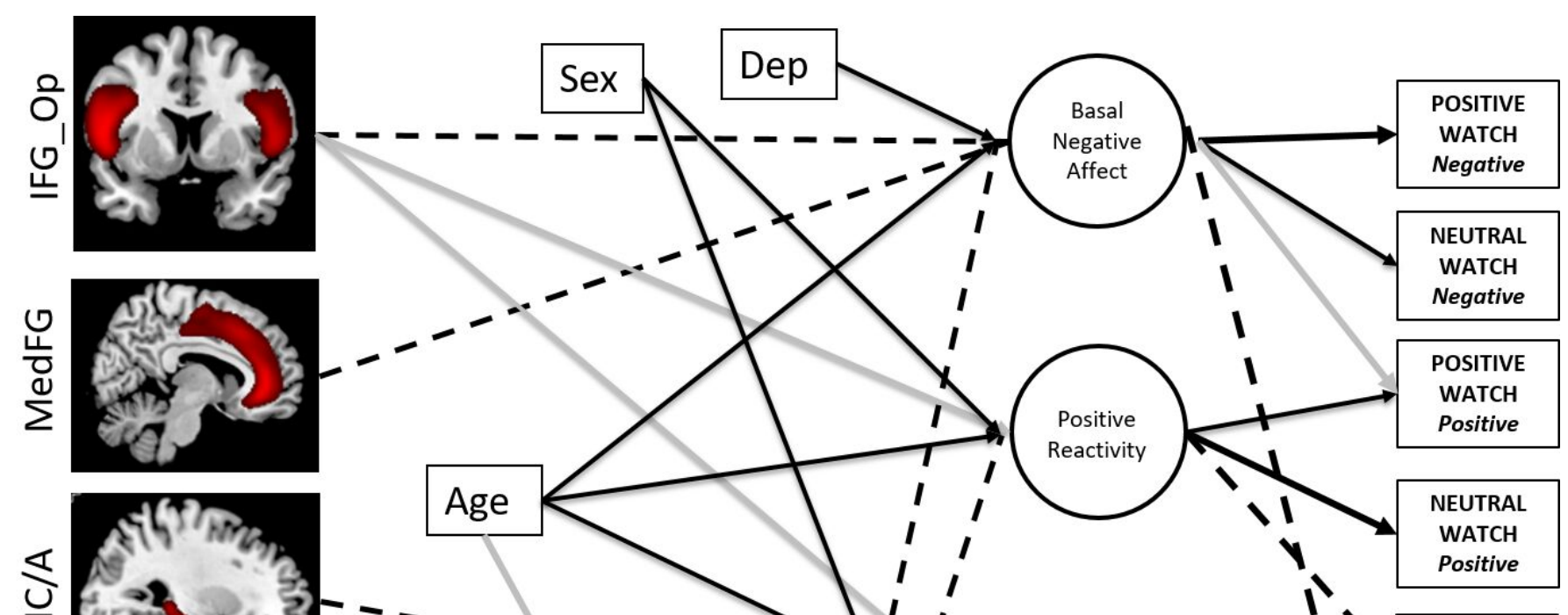

0
0
0
0
0
0

$<$

0
0
0
$\frac{2}{3}$
2
2
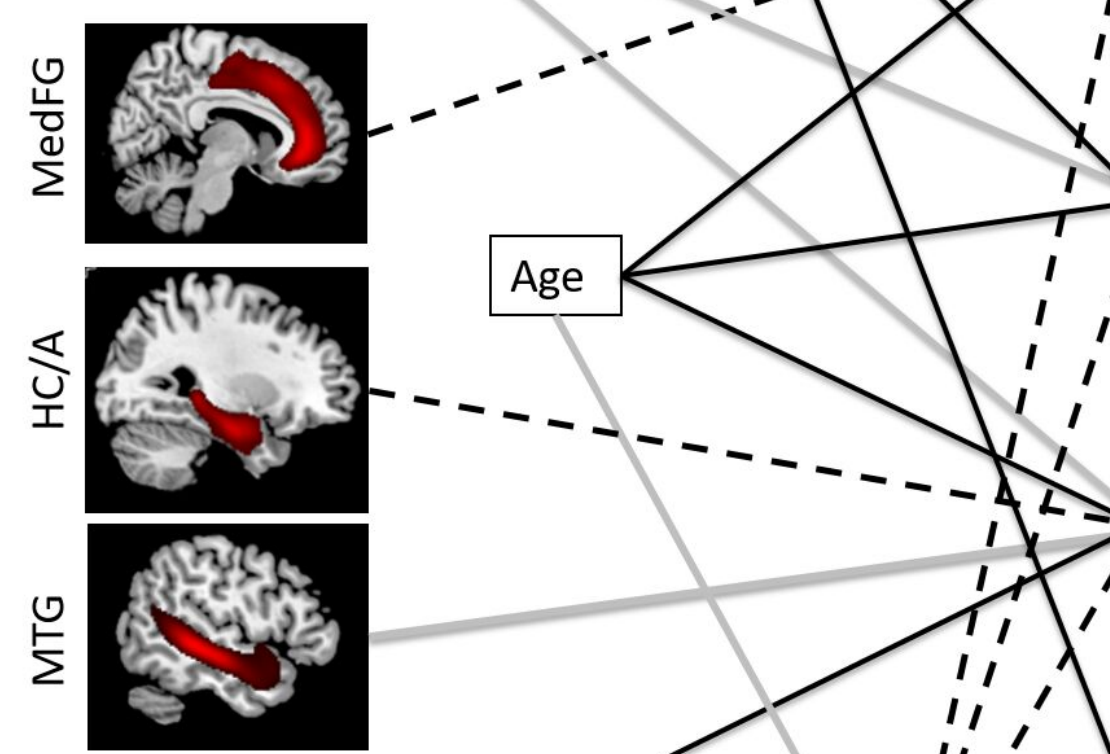

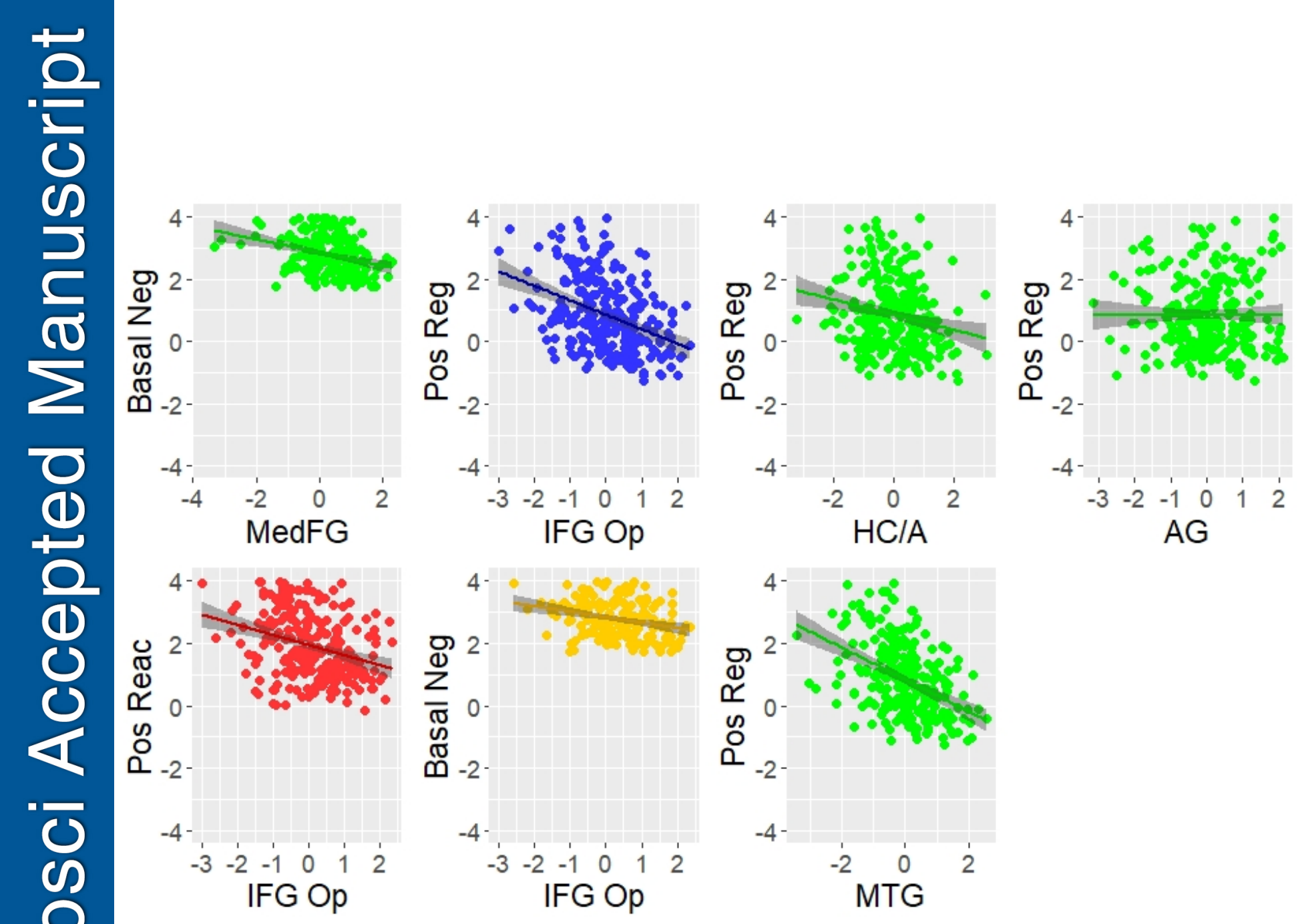